\title{
Ocular manifestations of atopic dermatitis
}

\begin{abstract}
Purpose: A review of the published literature on the history, pathogenesis, and treatment of atopic dermatitis (AD) and its ocular involvement.

Methods: Literature searches were conducted in MEDLINE (Ovid) and Google scholar for AD and ocular AD.

Results: AD is an inflammatory dermatosis that has classic presentations on the skin at different age points. The primary immunological profile is a Th2 profile, releasing an abundance of IL4 and IL10 both systemically and locally. AD can involve the eye and have devastating consequences. Here we review the latest understanding of AD pathogenesis and treatments vis-à-vis the ocular surface.
\end{abstract}

Conclusion: Ocular $\mathrm{AD}$ is a common manifestation of $\mathrm{AD}$. The newest drugs for systemic AD might be deleterious for ocular AD.

Keywords: atopic dermatitis, eczema, ocular eczema, keratoconus, filaggrin, dupilumab
Volume 3 Issue 2 - 2019

\author{
Omeed Michael Memar,' Sayena Jabbehdari, ${ }^{2}$ \\ Benjamin Cauglin, $3,4,5,6$ Ali R Djalilian ${ }^{2}$ \\ 'Academic Dermatology \& Skin Cancer Institute, USA \\ ${ }^{2}$ Department of Ophthalmology, University of Illinois Health \\ Hospital System, USA \\ ${ }^{3}$ Department of Surgery/Division of Otolaryngology,Jr. Hospital \\ of Cook County, USA \\ ${ }^{4}$ Hospital of Cook County, Chicago, USA \\ ${ }^{5}$ Division of Facial Plastic and Reconstructive Surgery, Jesse \\ Brown VA Medical Center, USA \\ ${ }^{6}$ Division of Facial Plastic and Reconstructive Surgery, University \\ of Illinois Health Hospital System, USA
}

Correspondence: Omeed Memar,Academic Dermatology and Skin Cancer Institute, I 30 N. Garland Ct, Chicago, IL 60602, USA, Tel 3 I 22300 I 80,Email omeedmemar@gmail.com

Received: February 24, 2018 | Published: March 07, 2019

\section{Introduction}

Atopic dermatitis (AD) is referred to as the itch before the rash, and is a chronic skin inflammation that has systemic manifestations. $\mathrm{AD}$ constitutes the most common form of inflammatory skin condition. ${ }^{2}$ It commonly presents in childhood before the age of 6 in up to $80 \%$ of cases, ${ }^{3}$ but $7-10 \%$ can present in adulthood. ${ }^{4}$ Other than the skin manifestations, AD patients for example have a higher incidence of psychological diagnoses, inflammatory bowel disease and joint inflammation. ${ }^{5} \mathrm{AD}$ competes with rosacea as the two common dermatologic conditions with the most ocular and periocular findings. We will review the pertinent elements of ocular AD.

\section{Clinical presentation of ocular atopic dermatitis}

AD commonly presents with asthma, hay fever, rhinitis, and allergic conjunctivitis that run-in families, but $20-30 \%$ lack such associations. ${ }^{6}$ A systematic review showed that $\mathrm{AD}$ patients have more contact sensitivities than the general population. ${ }^{7}$ The most common ocular allergens include aminoglycoside antibiotics, corticosteroids, wool alcohols, thiomersal, and benzalkonium chloride. ${ }^{8}$ Therefore, when topical sensitivity is suspected, a patch test could help in disease management.

AD presents in childhood with red, crusted patches and subsequent lichenification from chronic itching on the flexor surfaces of the extremities, face, eyelids, scalp, and other body parts. AD has a wide spectrum of clinical presentations, from itching in the flexor areas, to erythroderma, a true dermatologic emergency. Eyes can present with chronic blepharitis peri-ocular lichenification, hyperpigmentation (allergic shiners) and excessive skin fold (Dennie-Morgan fold), conjunctivitis, corneal neovascularization, keratoconus, herpes simplex keratitis, and rarely blindness. It has a sinusoidal clinical course, with times of flare and calm, but in some cases, it can be chronic in presentation (Figure 1). ${ }^{9}$

\section{Pathogenesis of ocular atopic dermatitis}

Although the dogma of AD pathogenesis was an IgE-mediated disease, newer data show that IgE involvement is a secondary phenomenon, and not the causative factor of a defective tissue barrier. ${ }^{10}$ A faulty epidermal barrier can have multiple causes, one being a lack of filaggrin $(F l g)$. Other causes of barrier dysfunction are physical itching secondary to Th2 cytokine release. ${ }^{11}$ Other factors include elevated lesional skin $\mathrm{Ph}^{12}$ with increased trans-epidermal water loss (TEWL) and increase permeability to external irritants and allergens..$^{13}$ This process makes AD skin more susceptible to harboring bacteria. ${ }^{14}$ Furthermore, there is an imbalance in epidermal protease/ protease inhibitor balance, ${ }^{15}$ in the epidermal lipid compositions and arrangement; ${ }^{16}$ decreased tight junction protein expression; $;{ }^{17}$ increased release of pro-inflammatory alarmins. ${ }^{18}$ Exposure of patients to presensitized antigens can exasperate $\mathrm{AD}$ (Figure 2) ${ }^{19}$ However, in the barrier enhancement for eczema prevention (BEEP) study, the use of emollients in infancy is protective against $\mathrm{AD} .^{20}$

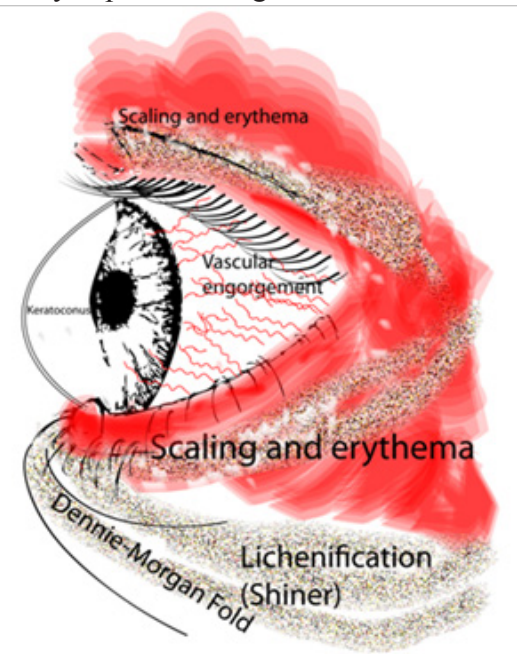

Figure I Clinical illustration of ocular atopic dermatitis.

\section{Immune System in atopic dermatitis}

Dermal infiltrates in $\mathrm{AD}$ lesions constitute $\mathrm{CD} 4+\mathrm{T}$ cells and dendritic antigen presenting cells. ${ }^{21}$ Specifically, Th2 products, IL-4, 
IL-10 and IL-13 are upregulated; moreover, Th22 secreting IL-22 22 and Th17 secreting IL17 are upregulated. ${ }^{23}$ Most AD patients have $\operatorname{IgE}$ to air-bone allergens, food allergens, microbial proteins ${ }^{24}$ and keratinocyte specific antigens..$^{25}$ Even non-affected skin in $\mathrm{AD}$ patients show inflammation that is analogous to lesional inflammation. ${ }^{22} \mathrm{As} A D$ waxes and wanes, there is an increased infiltration of Th2, Th17, and Th22 cells in the lesional skin. ${ }^{23}$ The Th2 and Th22 cytokines induce barrier dysfunction. ${ }^{26}$ Upon epithelial barrier disruption, alarmins become abundant. Langerhans cells and Th2 cells induce abundant IL-4 and IL-13. This cytokine profile induces immunoglobulin switching to antigen-specific IgE through the signal transducer and activator of transcription (STAT) and the IL-13 induces itch.

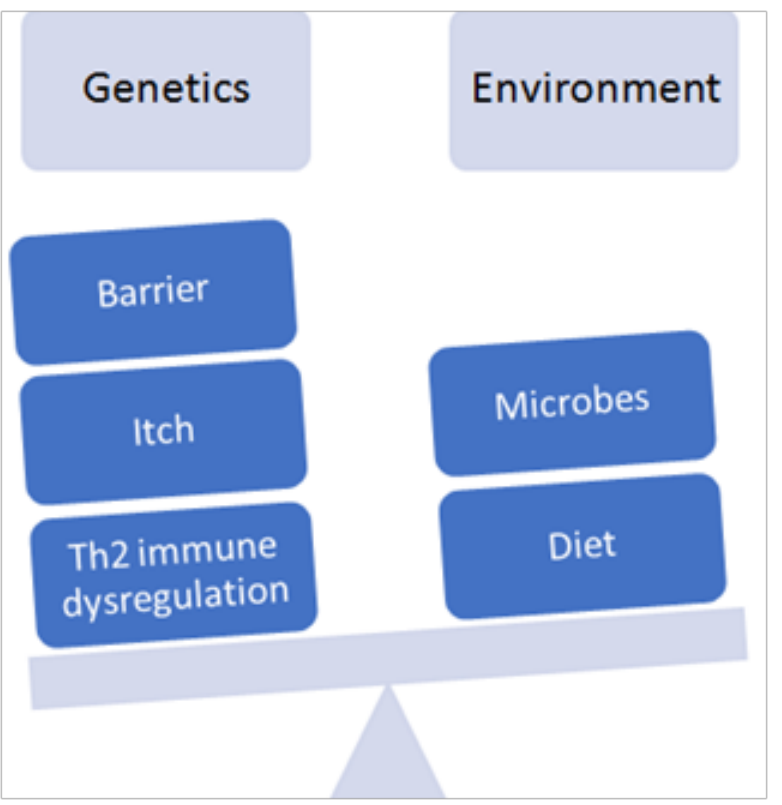

Figure 2 Pathogenic elements of ocular atopic dermatitis.

\section{Genetics of atopy}

The most common predisposing factor to acquiring $\mathrm{AD}$ is family history. If one parent has atopy, the offspring risk of AD is 3-fold, and if both parents have atopy, the offspring's risk is of AD is 5-fold. ${ }^{27}$ Studies of identical twins place genetic causality at $75 \%{ }^{28}$ Filaggrin ( Flg) mutation resulting in reduced expression of $\mathrm{Flg}$ is seen in $20 \%$ of $\mathrm{AD}$ patients, and constitutes the greatest genetic association with AD. ${ }^{29}$ However, in the general population, more than $50 \%$ have $\mathrm{Flg}$ mutations without any atopy. ${ }^{30}$ This indicates other needed factors in the development of AD. However, Flg is a complex protein of the stratum corneum and epidermal barrier with multiple variants. Its part of the $\mathrm{AD}$ manifestation, but not the whole story. ${ }^{31}$ Another genetic association is on chromosome 5 , at a stretch that controls Th2 cytokines, itch, and Th switching. ${ }^{32}$

\section{Itch}

The itch from $\mathrm{AD}$ is conducted by slow-conducting and fast conducting myelinated fibers, ${ }^{33}$ and can be heightened by emotional stress. ${ }^{34}$ Fibroblasts and keratinocytes in AD patients produce artemin, which induces greater innervation and hypersensitivity. ${ }^{35}$ One known inducer of artemin production is air pollution via stimulation of keratinocyte aryl hydrocarbon receptors. ${ }^{36}$ Thymic stromal lymphopoietin (TSLP) is a keratinocyte-derived cytokine that contributes to itch in $\mathrm{AD}$. However, the most common itch- causing agent is histamine from mast cells and basophils, ${ }^{37}$ followed by endothelin-1, IL-4, IL-13 and IL-31, but IL-31 is the predominant itch-inducing cytokine I n AD (Figure 3). ${ }^{38}$

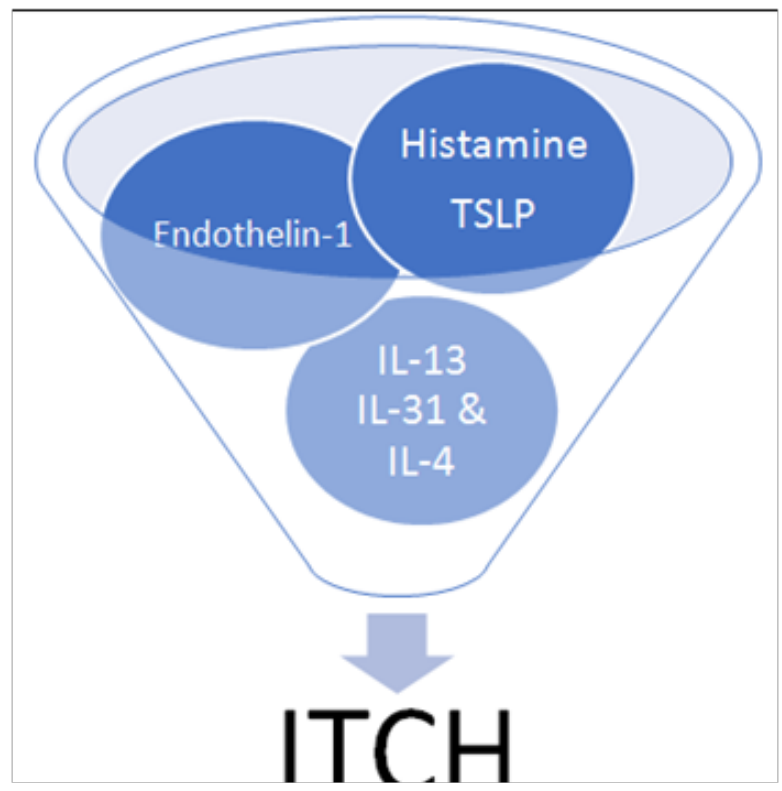

Figure 3 Itch causing endogenous agents in AD.

\section{Microbes}

Patients with $\mathrm{AD}$ have an altered innate immune system that allows for an overgrowth of bacteria, especially Staph. ${ }^{39}$ Staph and other microbes, release multiple enzymes that degrade tissue and disrupt barrier. The different elements that exacerbate AD can interplay. In one study, food allergy was linked to Staph colonization in children with $\mathrm{AD}{ }^{40}$ This bacterial enzymatic phenomenon of $\mathrm{AD}$ extends to ocular $\mathrm{AD}$, especially in cases of chronic $\mathrm{AD}$ blepharitis. ${ }^{41}$ However, "good" GI and bacteria have some beneficial effects. During pregnancy, ingestion of probiotics has mild protection for the fetus. ${ }^{42}$

\section{Diet}

Thirty seven percent of infants suffering from AD have a concomitant food allergy, while $10 \%$ of adults with $\mathrm{AD}$ have food allergies. ${ }^{43} \mathrm{AD}$ tends to precede food allergies in most cases,${ }^{44}$ and early introduction of allergy-inducing foods can cause tolerance to the food. ${ }^{45}$ However, peanut allergy can remain after childhood, while egg and milk allergies tend to be transient in childhood. ${ }^{46}$ Other associations with AD include diets rich in simple sugars, diets rich in polyunsaturated fats. Food allergy test, in the form of RAST or skin prick testing, is not indicated in the workup of $\mathrm{AD}$, except in recalcitrant forms in patients $<5$ years of age or in patients with immediate food-related flares. There is no evidence that delaying solid food to infants, or avoiding early use of antibiotics, or the consumption of fish oil protects against AD.

\section{Environmental elements}

Asthma and rhinitis and the most common occurrences with AD. ${ }^{47}$ Any air-borne allergen exposure occurs post-infancy. This exposure can flare $\mathrm{AD} .{ }^{48}$ Other associations with $\mathrm{AD}$ include proximity to urban or inner-city environment, areas with low ultraviolet light, multiple courses of antibiotics prior to age 5 , climates with low humidity, small families, and higher educated families. Furthermore, tobacco smoke 
increases $\mathrm{AD}$ risk, and should be avoided. There is no evidence that avoiding farm animals protects against $\mathrm{AD}$.

\section{Systemic Associations with atopic dermatitis}

$\mathrm{AD}$ is most commonly associated with systemic findings in the form of psychological diagnoses and autoimmune diseases. Attention deficit disorder, depression and autism have been linked to childhood $\mathrm{AD} .{ }^{49}$ The association of $\mathrm{AD}$ with depression extends into adulthood. ${ }^{50}$ There is some association with inflammatory bowel disease, rheumatoid arthritis, ${ }^{51}$ alopecia areata and vitiligo ${ }^{52}$ Cutaneous $\mathrm{T}$ cell lymphoma could be a risk factor in $\mathrm{AD} .^{53}$ The association of $\mathrm{AD}$ and cardiovascular disease is an ongoing debate, ${ }^{54}$ but a recent study identified a notable association of AD with heart disease. ${ }^{55}$

\section{Treatment of ocular atopic dermatitis and conclusion}

The treatment of ocular atopic dermatitis includes establishing hydration, eliminating bacterial colonization, treating any herpetic infection, and reducing the overall inflammation. Atopic dermatitis has periods of activity and periods of inactivity. A regimen is required to suppress the activity in its height, and prevent an active spike during the calm period. Ocular AD can have severe manifestations, and with the proper management and treatment, the sever manifestation of $\mathrm{AD}$ can be avoided (Figure 4).

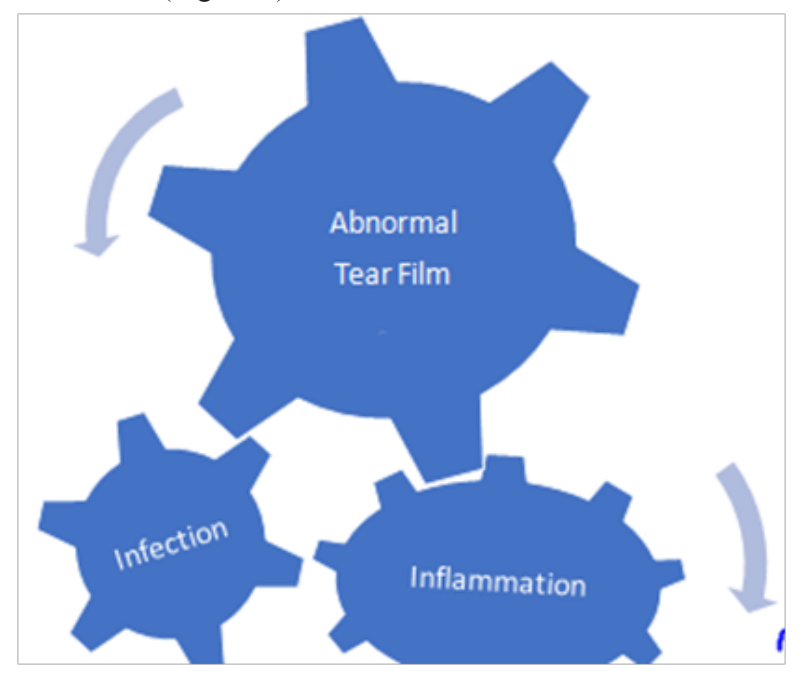

Figure 4 The main elements of ocular atopic dermatitis.

Hydration of the tear film is accomplished by regaining meibomian and lacrimal glandular health (Figure 4). In the meantime, hydrating eye drops are needed to protect the ocular surface, such as over-thecounter drops (preferably preservative free) can be used $4-5 \mathrm{x}$ per day. Hydrating eye drops can be used less frequently during the inactive period of ocular atopic dermatitis. Topical anti-histamine + mast cell stabilizers are also used routinely in ocular AD patients.

Staph and other bacteria tend to colonize skin and mucosa, including the ocular lash line. Their presence is accompanied with stimulation of the innate immune system and their toxins can activate the adaptive immune system. This causes pro-inflammatory cytokine release, swelling, and angiogenesis on the ocular surface. Furthermore, herpes simplex virus can be reactivated in severe cases, i.e., eczema herpeticum. A lytic virus on the ocular surface is quite devastating. Therefore, it is imperative to identify pathogens that occupy lesional tissue. For bacteria, ocular erythromycin ointment is both antibacterial, anti-angiogenic, endothelin-1-blocking, ${ }^{56}$ and helps trap moisture. In more severe cases, oral antibiotics, like amoxicillin with clavulanate is recommended for a period of 10days. If there are signs of a herpetic reactivation, then topical/oral antivirals are recommended.

The most important aspect of $\mathrm{AD}$ is inflammation. The tissue integrity and barrier repair are contingent on an appropriate antiinflammatory regimen. Topical steroids, like prednisolone eye drops, are a first line drug, but should not be used for extended periods. Therefore, with the steroid, a steroid-sparing agent, like ocular cyclosporin (or tacrolimus), make for a good combination. After the a few weeks, the steroids are tapered off, and the cyclosporin is continued. If the symptoms are more severe, a short course of oral methylprednisolone taper for 5 days is effective. Anti-histamines are commonly used; however, their anti-cholinergic effect can exacerbate the tear film dysfunction. Recently, a new biologic targeting the IL-4 receptor, dupilumab, has been FDA approved for moderate-to-severe atopic dermatitis. However, dupilumab has been associated with druginduced conjunctivitis. This makes us cautious in recommending it for severe $\mathrm{AD}$ with ocular manifestations ${ }^{57}$ Latest though on $\mathrm{AD}$ is that there is an imbalance of the skin flora, and potentially the periocular flora. When virulent strains of Staph dominate the flora, disease occurs, and when non-virulent microbes dominate, skin barrier is protected. The establishment of a healthy microbiome will be the next exciting approach to $\mathrm{AD}$, and possibly ocular $\mathrm{AD} .^{58}$

\section{Acknowledgments}

\section{None}

\section{Conflicts of interest}

The authors declare no conflicts of interest.

\section{References}

1. Hong J, Buddenkotte J, Berger TG, et al. Management of Itch in Atopic Dermatitis. Semin Cutan Med Surg. 2011;30(2):71-86.

2. Deckers IA, McLean S, Linssen S, et al. Investigating international time trends in the incidence and prevalence of atopic eczema 19902010: a systematic review of epidemiological studies. PLOS ONE. 2012;7(7):e39803.

3. Perkin MR, Strachan DP, Williams HC, et al. Natural history of atopic dermatitis and its relationship to serum total immunoglobulin $\mathrm{E}$ in a population-based birth cohort study. Pediatr Allergy Immunol. 2004;15(3):221-229.

4. Abuabara K, Yu AM, Okhovat JP, et al. The prevalence of atopic dermatitis beyond childhood: A systematic review and meta-analysis of longitudinal studies. Allergy. 2017;73(3):696-704.

5. Dalgard FJ, Gieler U, Tomas-Aragones L, et al. The psychological burden of skin diseases: a cross-sectional multicenter study among dermatological out-patients in 13 European countries. J Invest Dermatol. 2015;135(4):984-991.

6. Flohr C, Johansson SG, Wahlgren CF, et al. How atopic is atopic dermatitis? J Allergy Clin Immunol. 2004;114(1):150-158.

7. Hamann CR, Hamann D, Edeberg A, et al. Association between atopic dermatitis and contact sensitization: A systematic review and metaanalysis. J Am Acad Dermatol. 2017;77(1):70-78.

8. Gilissen L, Dedecker L, Hulshagen T, et al. Allergic contact dermatitis from topical ophthalmic medications: keep an eye on it! Contact Dermtitis. 2019. 
9. Garmhausen D, Hagemann T, Bieber T, et al. Characterization of different courses of atopic dermatitis in adolescent and adult patients. Allergy. 2013;68(4):498-506.

10. Tsakok T, Marrs T, Mohsin M, et al. Does atopic dermatitis cause food allergy? A systematic review. J Allergy Clin Immunol. 2016;137(4):1071-1078.

11. Seltmann J, Roesner LM, von Hesler FW, et al. IL-33 impacts on the skin barrier by downregulating the expression of filaggrin. J Allergy Clin Immunol. 2015;135(6):1659-1661.

12. Jungersted JM, Scheer H, Mempel M, et al. Stratum corneum lipids, skin barrier function and filaggrin mutations in patients with atopic eczema. Allergy. 2010;65(7):911-918.

13. Halling-Overgaard AS, Kezic S, Jakasa I, et al. Skin absorption through atopic dermatitis skin: a systematic review. $\mathrm{Br} J$ Dermatol. 2017;177(1):84-106.

14. Miajlovic H, Fallon PG, Irvine AD, et al. Effect of filaggrin breakdown products on growth of and protein expression by Staphylococcus aureus. J Allergy Clin. Immunol. 2010;126(6):1184-1190 e3.

15. Igawa S, Kishibe M, Minami-Hori M, et al. Incomplete KLK7 Secretion and upregulated LEKTI expression underlie hyperkeratotic stratum corneum in atopic dermatitis. J Invest. Dermatol. 2017;137(2):449-456.

16. Janssens M, van Smeden J, Gooris GS, et al. Increase in shortchain ceramides correlates with an altered lipid organization and decreased barrier function in atopic eczema patients. $J$ Lipid Res. 2012;53(12):2755-2766.

17. De Benedetto A, Rafaels NM, McGirt L, et al. Tight junction defects in patients with atopic dermatitis. J Allergy Clin Immunol. 2011;127(3):773-786 e1-7.

18. Yoon J, Leyva-Castillo M, Wang G, et al. IL-23 induced in keratinocytes by endogenous TLR4 ligands polarizes dendritic cells to drive IL-22 responses to skin immunization. $J$ Exp Med. 2016;213(10):2147-2166.

19. Werfel T, Heratizadeh A, Niebuhr M, et al. Exacerbation of atopic dermatitis on grass pollen exposure in an environmental challenge chamber. J Allergy Clin Immunol. 2015;136(1):96-103.

20. Chalmers JR, Haines RH, et al. Effectiveness and cost-effectiveness of daily all-over-body application of emollient during the first year of life for preventing atopic eczema in high-risk children (The BEEP trial): protocol for a randomized controlled trial. Trials. 2017;18(1):343.

21. Yoshida K, Kubo A, Fujita H, et al. Distinct behavior of human Langerhans cells and inflammatory dendritic epidermal cells at tight junctions in patients with atopic dermatitis. $J$ Allergy Clin Immunol. 2014;134(4):856-864.

22. Gittler JK, Shemer A, Suárez-Fariñas M, et al. Progressive activation of $\mathrm{T}(\mathrm{H}) 2 / \mathrm{T}(\mathrm{H}) 22$ cytokines and selective epidermal proteins characterizes acute and chronic atopic dermatitis. $J$ Allergy Clin Immunol. 2012;130(6):1344-1354.

23. Noda S, Suárez-Fariñas $\mathrm{M}$, Ungar $\mathrm{B}$, et al. The Asian atopic dermatitis phenotype combines features of atopic dermatitis and psoriasis with increased TH17 polarization. J Allergy Clin Immunol. 2015;136(5):1254-1264.

24. Sonesson A, Bartosik J, Christiansen J, et al. Sensitization to skinassociated microorganisms in adult patients with atopic dermatitis is of importance for disease severity. Acta Derm Venereol. 2013;93(3):340 345.

25. Tang TS, Bieber T, Williams HC. Does "autoreactivity" play a role in atopic dermatitis? J Allergy Clin Immunol. 2012;129(5):1209-1215.
26. Hamid Q, Boguniewicz M, Leung DY. Differential in situ cytokine gene expression in acute versus chronic atopic dermatitis. $J$ Clin Invest. 1994;94(2):870-876.

27. Wadonda-Kabond N, Sterne JA, Golding J, et al. Association of parental eczema, hayfever, and asthma with atopic dermatitis in infancy: birth cohort study. Arch Dis Child. 2004;89(10):917-921.

28. Thomsen SF, Ulrik CS, Kyvik KO, et al. Importance of genetic factors in the etiology of atopic dermatitis: a twin study. Allergy Asthma Proc. 2007;28:535-539

29. Irvine A, McLean WH, Leung DY. Filaggrin mutations associated with skin and allergic diseases. N Engl J Med. 2011;365(14):1315-1327.

30. Weidinger S, O’Sullivan M, Illig T, et al. Filaggrin mutations, atopic eczema, hay fever, and asthma in children. J Allergy Clin Immunol. 2008;121(5):1203-1209.

31. Brown SJ, Kroboth K, Sandilands A, et al. Intragenic copy number variation within filaggrin contributes to the risk of atopic dermatitis with a dose-dependent effect. J Invest Dermatol. 2012;132(1):98-104.

32. Koh BH, Hwang SS, Kim JY, et al. Th2 LCR is essential for regulation of Th2 cytokine genes and for pathogenesis of allergic asthma. Proc Natl Acad Sci USA. 2010;107(23):10614-10619.

33. Bautista DM, Wilson SR, Hoon MA. Why we scratch an itch: the molecules, cells and circuits of itch. Nat Neurosci. 2014;17(2):175-182.

34. Sanders KM, Akiyama T. The vicious cycle of itch and anxiety. Neurosci Biobehav Rev. 2018;87:17-26.

35. Murota H, Izumi M, Abd El-Latif MI, et al. Artemin causes hypersensitivity to warm sensation, mimicking warmth-provoked pruritus in atopic dermatitis. J Allergy Clin Immunol. 2012;130(3):671$682 \mathrm{e} 4$.

36. Kabashima K, Otsuka A, Nomura T. Linking air pollution to atopic dermatitis. Nat Immunol. 2016;18(1):5-6.

37. Bautista DM, Wilson SR, Hoon MA. Why we scratch an itch: the molecules, cells and circuits of itch. Nat Neurosci. 2014;17(2):175-182.

38. Wilson SR, Thé L, Batia LM, et al. The epithelial cell-derived atopic dermatitis cytokine TSLP activates neurons to induce itch. Cell. 2013;155(2):285-295.

39. Geoghegan JA, Irvine AD, Foster TJ. Staphylococcus aureus and Atopic Dermatitis: A Complex and Evolving Relationship. Trends Microbiol. 2018;26(6):484-497.

40. Jones AL, Curran-Everett D, Leung DYM. Food allergy is associated with Staphylococcus aureus colonization in children with atopic dermatitis. J Allergy Clin Immunol. 2016;137:1247-1248.e3.

41. Dougherty JM, McCulley JP. Bacterial lipases and chronic blepharitis Invest Ophthalmol Vis Sci. 1986;27’4):486-491.

42. Panduru M, Panduru NM, Salavastru CM, et al. Probiotics and primary prevention of atopic dermatitis: a meta $\square$ analysis of randomized controlled studies. J Eur Acad Dermatol Venereol. 2015;29(2);232-242.

43. Manam S, Tsakok T, Till S, et al. The association between atopic dermatitis and food allergy in adults. Curr Opin Allergy Clin Immunol. 2014;14(5):423-429.

44. Renz H, Allen KJ, Sicherer SH, et al. Food allergy. Nat Rev Dis Primers. 2018;4:17098

45. du Toit G, Sayre PH, Roberts G, et al. Allergen specificity of early peanut consumption and effect on development of allergic disease in the learning early about peanut allergy study cohort. J. Allergy Clin Immunol. 2018;141(4):1343-1353. 
46. Longo G, Berti I, Burks AW, et al. IgE-mediated food allergy in children Lancet. 2013;382(9905):1656-1664.

47. Kapoor R, Menon C, Hoffstad O, et al. The prevalence of atopic triad in children with physician-confirmed atopic dermatitis. J Am Acad Dermatol. 2008;58(1):68-73.

48. Werfel T, Heratizadeh A, Niebuhr M, et al. Exacerbation of atopic dermatitis on grass pollen exposure in an environmental challenge chamber. J Allergy Clin Immunol. 2015;136(1):96-103.

49. Yaghmaie P, Koudelka CW, Simpson EL. Mental health comorbidity in patients with atopic dermatitis. $J$ Allergy Clin Immunol. 2013;131(2):428-433.

50. Thyssen JP, Hamann CR, Linneberg A, et al. Atopic dermatitis is associated with anxiety, depression, and suicidal ideation, but not with psychiatric hospitalization or suicide. Allergy. 2017;73(1):214-220.

51. Andersen YM, Egeberg A, Gislason GH, et al. Autoimmune diseases in adults with atopic dermatitis. J Am Acad Dermatol. 2017;76(2):274 $280 \mathrm{e} 1$.

52. Sorrell J, Petukhova L, Reingold R, et al. Shedding light on alopecia areata in pediatrics: a retrospective analysis of comorbidities in children in the national alopecia areata registry. Pediatr Dermatol. 2017;34(5):e271-e272.
53. Legendre L, Barnetche T, Mazereeuw-Hautier J, et al. Risk of lymphoma in patients with atopic dermatitis and the role of topical treatment: a systematic review and meta-analysis. J Am Acad Dermatol. 2015;72(6):992-1002.

54. Drucker AM, Qureshi AA, Dummer TJB, et al. Atopic dermatitis and risk of hypertension, type 2 diabetes, myocardial infarction and stroke in a cross-sectional analysis from the Canadian partnership for tomorrow project. Br J Dermatol.2017;177(4):1043-1051.

55. Ingram JR. Atopic eczema and cardiovascular disease. BMJ. 2018; 361:k2064.

56. Takizawa H, Desaki M, Ohtoshi T, et al. Erythromycin and clarithromycin attenuate cytokine-induced endothelin-1 expression in human bronchial epithelial cells. Eur Respir J. 1998;12(1):57-63.

57. Treister AD, Kraff-Cooper C, Lio PA. Risk Factors for DupilumabAssociated Conjunctivitis in Patients with Atopic Dermatitis. JAMA Dermatology. 2018;154(10):1208-1211.

58. Myles IA, Williams KW, Reckhow JD, et al. Transplantation of human skin microbiota in models of atopic dermatitis. JCI Insight. 2016;1(10). pii. 86955 . 